\title{
RESEARCH NOTES \\ PRELIMINARY MEASUREMENTS OF NET RADIATION AND EVAPORATION OVER BARE SOIL AND FALLOW BUSHLAND IN THE SAHEL
}

\author{
J.S. WALLACE AND J.H.C. GASH \\ Institute of Hydrology, Wallingford, Oxon, OXIO 8BB, UK \\ AND \\ M. V. K. SIVAKUMAR \\ ICRISAT Sahelian Center, BP 12404, Niamey, Niger
}

Received 7 August 1989

Revised 13 October 1989

\begin{abstract}
Net radiation and evaporation are compared over two contrasting land surfaces, fallow bushland and bare soil, in Niger, West Africa. Data are presented for 6 days, before and after a large rainstorm $(39 \mathrm{~mm})$, which illustrate how evaporation from the bush vegetation changed little in comparison with the larger change in evaporation observed over the bare soil. Net radiation over the bush vegetation was 20 per cent greater than that over the dry bare soil, but only 12 per cent greater than that over wet bare soil. These differences are consistent with the expected difference in albedo and surface temperature of the two surfaces.
\end{abstract}

KEY WORDS Net radiation Evaporation Bare soil Bushland Sahel

\section{INTRODUCTION}

The widespread deterioration of large areas of savannah in the semi-arid regions of Africa is believed to be associated with the overexploitation of marginal land via the removal of fuel wood and overgrazing (e.g. see Barrow, 1987). Whatever the cause, the net effect is to degrade the savannah vegetation to the point where sizeable areas of bare soil appear between the vegetation. The proportion of bare soil is a measure of the degree of degradation; in the limit there is no vegetation left, just bare sandy soil. The extent to which this process of land degradation is reversible may depend on whether there is any concurrent change in climate. Modelling studies of the Sahel have indicated that replacing the vegetation by bare soil may modify the climate in such a way as to reduce rainfall (see Rowntree and Sangster, 1986). However, these modelling studies were based on fairly simple land surface parameterizations and also suffer from a lack of basic data against which they can be calibrated. Furthermore, the predictions of these models are very sensitive to the land surface conditions. For example. Cunnington and Rowntree (1986) have shown that the rate of evaporation (via soil moisture) and net radiation (via albedo) have important effects on simulations of the Sahelian climate. There is, therefore, a need for more accurate information on the energy and water balance of vegetated and bare soil surfaces in the Sahelian environment.

This paper presents some preliminary results from experiments carried out in the southern Sahelian region of Niger. Differences in net radiation and evaporation between bare soil and fallow bushland are presented for 6 days with different surface soil moisture conditions.

0899-8418/90/020203-08\$05.00

(C) 1990 by the Royal Meteorological Society 


\section{SITE AND INSTRUMENTATION}

The experiment was carried out over two sites at the ICRISAT (International Crops Research Institute for the Semi-Arid Tropics) Sahelian Center, located at Sadoré, $45 \mathrm{~km}$ south of Niamey, Niger (latitude $13^{\circ} 15^{\prime} \mathrm{N}$, longitude $\left.2^{\circ} 17^{\prime} \mathrm{E}\right)$. The first site was an area $(800 \times 2000 \mathrm{~m})$ of fallow bushland containing three principal types of vegetation. The first group, constituting 78 per cent of the ground cover, was a mixed community of leguminous and grass species (predominantly Cassia mimosoides, Tephrosia linearis, Aristida mutabilis, and Eragrostis tremula). The second type of vegetation comprised woody shrubs about $2.5 \mathrm{~m}$ tall (Guiera senegalensis and Combretum glutinosum) covering approximately 19 per cent of the area and, thirdly, there were occasional trees (approximately 1.5 per hectare) between $5 \mathrm{~m}$ and $10 \mathrm{~m}$ tall (Balanites aegyptiaca).

The second site was a $200 \times 200 \mathrm{~m}$ field of bare soil containing a short stubble of pearl millet (Pennisetum americanum cv CIVT) which had been recently harvested. The soil in both fields was a Daybou Sand, full details are given by West et al. (1984).

At both sites, evaporation was measured using Institute of Hydrology Mk2 Hydras (Shuttleworth et al., 1988). On the larger bush site the Hydra was mounted on a mast at $5.5 \mathrm{~m}$, well above the legume-grass and woody shrubs. On the smaller bare soil field the Hydra was mounted at a lower height, $2 \mathrm{~m}$, to minimize contamination of the evaporative flux from surrounding crop fields. For comparison with actual evaporation measurements, potential evaporation was calculated for both the bush and soil sites using the Penman (1948) formula with measured values of net radiation. At both sites, net radiation was measured using polythene dome net radiometers (Didcot Instrument Co., Abingdon, UK). On the bush site the net radiometer was mounted $1 \mathrm{~m}$ above the legume-grass mixture, ignoring the bushes. The likely error from this is small $(<10$ per cent) since the bushes only occupied 19 per cent of the land and their net radiation should not differ greatly from that of the legume-grass mixture. However, it would be prudent to make further measurements of the spatial variability in net radiation within a fallow bushland site to check the validity of this assumption.

Hourly average measurements were made for 6 days between 5 and 10 September 1986. During this period the soil was fairly wet following $12 \mathrm{~mm}$ of rain on 4 September with a further $39 \mathrm{~mm}$ falling between 00.00 and 03.00 GMT on 8 September.

\section{RESULTS}

Figure 1 shows a comparison of net radiation measured over the bush vegetation and bare soil on 3 days. On the first day, 6 September 1986, Figure 1(a), the soil surface was dry and the net radiation over the bush was 21 per cent greater than that over the bare soil. Immediately following rain in the early morning of 8 September, net radiation over the bush was only 12 per cent greater than over the soil, Figure 1(b). On the following day when the soil surface had dried, bush net radiation returned to values 19 per cent greater than over the soil, Figure 1(c).

Figure 2 shows the diurnal course of evaporation from the bush and soil for the same 3 days as above. Evaporation from the bush changed little between the first 2 days, being slightly lower in the afternoon of the day after the rain, compared with the same period beforehand. Much of this difference, however, can be accounted for by the lower net radiation on 8 September, especially in the afternoon (see Figure 1). To normalize for differences in net radiation between days, the ratio of evaporation to net radiation for daylight hours ( 06.00 to 17.00 inclusive) was calculated on the 2 days. Before the rainstorm, 50 per cent of the net radiation was used for evaporation, whereas on the day of the rainstorm, evaporation increased only slightly to 56 per cent of net radiation, and by the following day had returned to 52 per cent of net radiation.

Figure 2 also shows a similar comparison of evaporation and net radiation over the bare soil field before and after rain. In contrast to the bush vegetation, evaporation from the soil increased markedly after rain, the amount of net radiation used to evaporate water rising from 50 per cent before rain to 65 per cent afterwards. On the first day (Figure 2(a)), evaporation from the soil $(2.8 \mathrm{~mm})$ was less than that from the bush $(3.6 \mathrm{~mm})$. However, since the fraction of net radiation used for evaporation was the same on both sites ( 50 per cent), the difference in evaporation can be accounted for by the difference in available energy. Figure 2(b) shows that after the rainstorm on 8 September, evaporation rates from the soil and bush were very similar. On this day, 


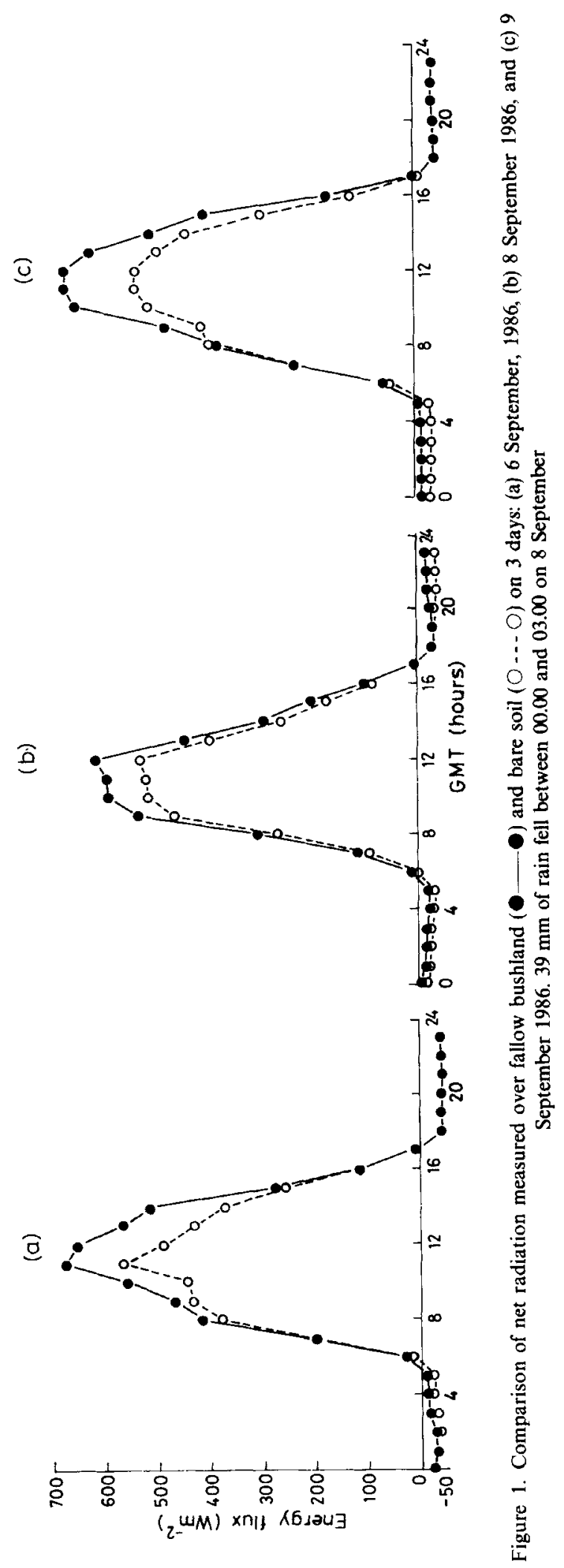




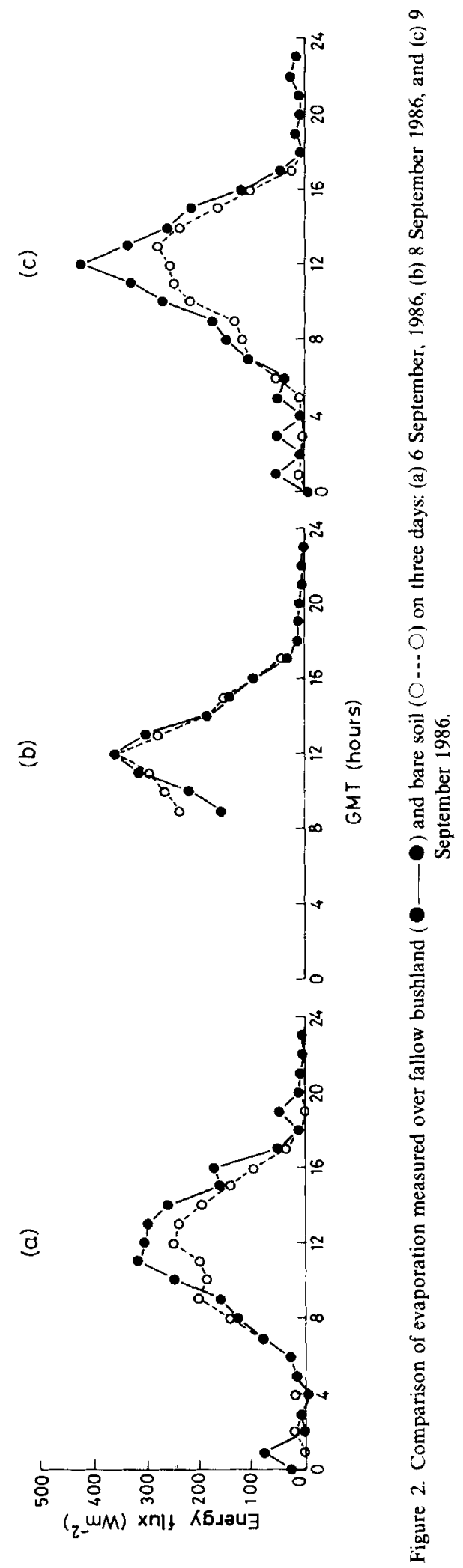


the albedo of the soil surface must have decreased when it was wet, therefore these equal evaporation rates could only be achieved by a greater proportion of available energy being used for evaporation from the soil. On the following day, Figure 2(c), the soil surface had dried and soil evaporation decreased again to rates lower than those from the bush; daily totals being 3.1 and $4.6 \mathrm{~mm}$ respectively.

Figure 3 shows the daily total actual and potential evaporation for a sequence of 6 days. Potential evaporation was greater for the bush site because of its higher net radiation. During the first 3 days, actual evaporation from both the soil and the bush decreased despite an increase in potential evaporation. After rain the evaporation from the soil increased, even though potential evaporation decreased. Despite the complexity of this behaviour, Figure 4 shows that the ratio of actual to potential evaporation for both of the sites was very similar on all of the days, except the one immediately following the rainstorm.

\section{DISCUSSION}

The energy balance of the soil and bush sites has been shown to be very different. Differences in net radiation can be caused by differences in albedo and/or surface temperatures. The albedo of sandy soils can vary widely, from 0.1 to 0.4 (e.g. Kondratyev, 1969; List, 1966); the lower figures being associated with wet soils. Previously unpublished measurements of albedo over the sandy soil at the ICRISAT site, Figure 5, indicate

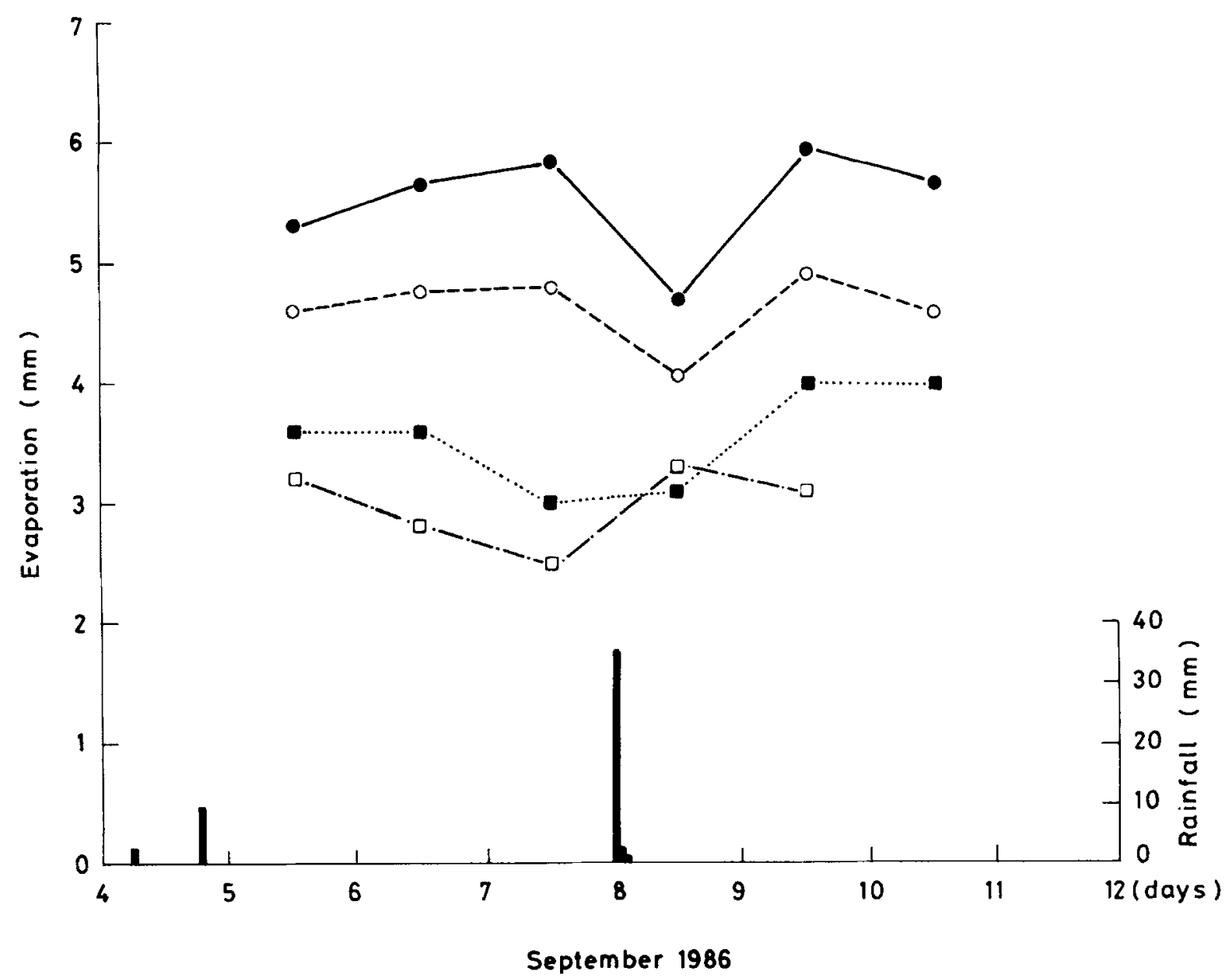

Figure 3. Variation in actual (squares) and potential (circles) evaporation from fallow bushland (a, $\mathbf{0})$ and bare soil ( $\square, \bigcirc)$ before and after rainfall 


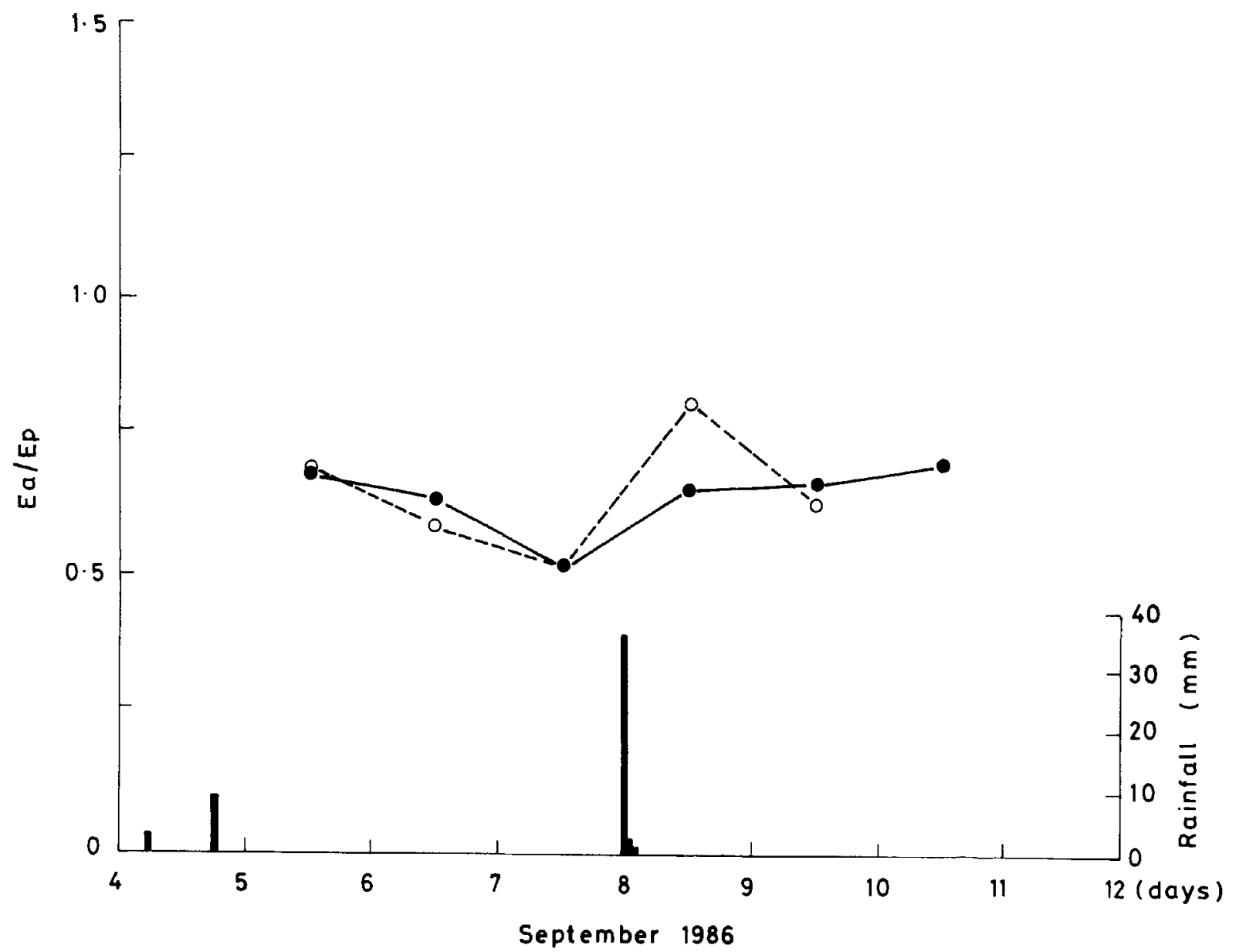

Figure 4. Variation in the ratio of actual $\left(E_{\mathrm{a}}\right)$ to potential evaporation $\left(E_{\mathrm{p}}\right)$ from fallow bushland $(-\infty)$ and bare soil $\left(O-\mathrm{O}^{-}\right.$ before and after rainfall

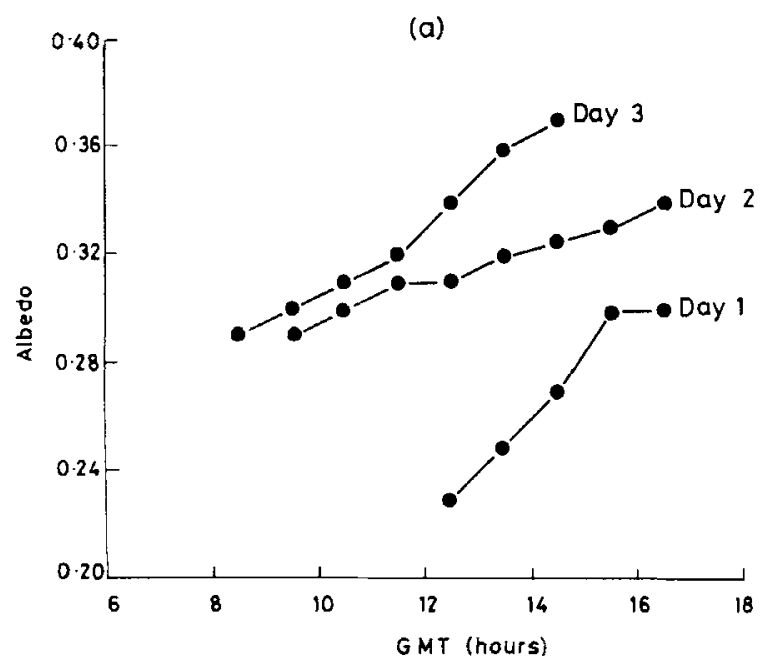

(b)
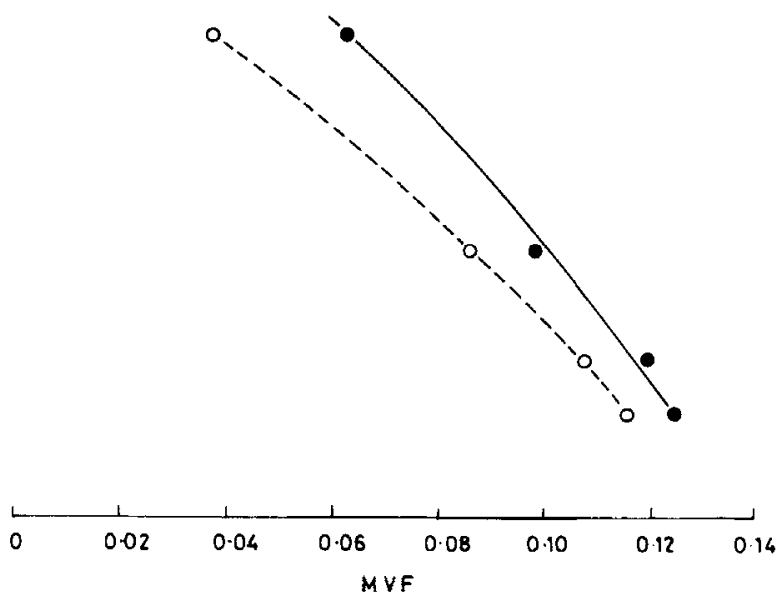

Figure 5. The change in bare soil albedo with (a) time after an initial saturation and (b) volumetric moisture content (MVF) of the top $25 \mathrm{~mm}(\mathrm{O} \ldots \mathrm{O})$ and $150 \mathrm{~mm}(-\ldots)$ of soil 
values of 0.24 when fully wetted, rising to around 0.38 as the soil dries; a process which took about 3 days in the absence of rain. Similar patterns of the temporal change in albedo of a bare (loam) soil have been reported by Idso et al. (1975), however, the absolute values and rates of change of albedo are very different here. The albedo of savannah vegetation in northern Nigeria has been reported by Oguntoyinbo (1970) as $0 \cdot 19$. These values of soil and bush albedo could explain most of the difference in net radiation observed in the present study. During the day, bare soil surface temperatures should be greater than those of the bush. This would further increase the difference in the net radiation over the two surfaces, by between $7 \mathrm{Wm}^{-2}$ and $8 \mathrm{Wm}^{-2}$ per degree $\mathrm{K}$ difference in temperature. The much larger net radiation over the bush, therefore, is consistent with the expected difference in albedo and surface temperature of the two surfaces. However, further measurements of the complete radiation balance are required to confirm this conclusion.

Evaporation from the soil and bush surfaces was similar when the soil had been recently wetted by rain. However, the soil surface dried very rapidly and evaporation rates decreased to values well below those in the bush. The data presented here were all collected within a short period of time when the soil was comparatively wet. Much larger differences in bush and soil evaporation would be expected under drier conditions and further measurements should be made to investigate this.

The sensitivity of the Sahelian climate to the surface albedo has been demonstrated in a series of modelling experiments (e.g. Charney et al., 1977; Cunnington and Rowntree, 1986; Rowntree, 1988) using global circulation models, in which the energy partition at the land surface was parameterized in terms of a potential evaporation modified by a factor related to soil moisture content. For bare or vegetated surfaces with a high soil moisture content, evaporation was assumed to occur at the potential rate, and to continue at that rate until a critical soil moisture content was reached. Only then was the estimated evaporation reduced below the potential rate. The data presented here confirm that the albedo is an important factor controlling the surface energy balance via its effect on net radiation and potential evaporation. The relation given here between albedo and water content for a typical Sahelian soil (Figure 5(b)) should, therefore, be of some value in modelling the climate of this region. We have also demonstrated that even when the soil is wet after substantial rain, actual evaporation rates may be markedly less than the potential rate currently assumed in many global circulation models.

To improve the performance of global circulation models, a new generation of more advanced land surface models are being developed. As well as responding to changes in albedo and soil moisture, these models (e.g. Dickinson, 1984; Dickinson et al., 1986; Sellers et al., 1986; Sellers and Dorman, 1987; Warrilow et al., 1986) have the capability to take account of the variation in surface roughness and stomatal response of different vegetation types. However, as models become more sophisticated they are also more demanding in terms of the calibration data that are required to evaluate their parameters. In the case of the Sahel very little suitable data are available. Clearly the collection of such data should be a high priority in any programme of research that aims to produce an understanding of the interaction between vegetation and climate, and its implications for land degradation. When these models are properly calibrated then the question of whether removal of vegetation in the Sahel changes evaporation and rainfall over the long term can be addressed more realistically.

\section{ACKNOWLEDGEMENT}

The data presented here were collected as part of a project funded by the UK Overseas Development Administration. We are grateful to all those members of the staff of the ICRISAT Sahelian Center who assisted us with the field work.

\section{REFERENCES}

Barrow, C. I. 1987. Water resources and agricultural development in the tropics (Longman development studies), Wiley, New York, pp. 356.

Charney, J. G., Quirk, W. J., Chow, S. H. and Kornfield, J. 1977, 'A comparative study of the effects of albedo change on drought in semi-arid regions', J. Atmos. Sci., 34, 1366-1385. 
Cunnington, W. M. and Rowntree, P. R. 1986. 'Simulations of the Saharan atmosphere: dependence on moisture and albedo', $Q . J l$. $R$. Meteorol. Soc., 112, 971-999.

Dickinson, R. E. 1984 'Modelling evapotranspiration for three-dimensional global climate models', In Hudson, J. E. and Takahashi, T. (Eds), Climate Processes and Climate Sensitivity, American Geophysics Union, Geophysics Monogram 19, pp. 58-72.

Dickinson, R. E., Henderson-Sellers, A., Kennedy, P. J. and Wilson, M. F. 1986. Biosphere-Atmosphere Transfer Scheme (BATS) for the NCAR Community Climate Model, National Center for Atmospheric Research, Boulder, Colorado, Technical Note/TN-275 + STR, pp. 69.

Idso, S. B., Jackson, R. D., Reginato, R. J., Kimball, B. A. and Nakayama, F. S. 1975. 'The dependence of bare soil albedo on soil water content', J. Appl. Meteorol., 14, 109-113.

Kondratyev, K. Ya. 1969. Radiation in the Atmosphere, Academic Press, New York, pp. 912.

List, P. J. 1966. Smithsonian Meteorological Tables, Smithsonian Miscellaneous Collection pp. 442-443.

Oguntoyinbo, J. S. 1970. 'Reflection coefficient of natural vegetation, crops and urban surfaces in Nigeria', Q.Jl. R. Meteorol. Soc., 96, $430-441$.

Penman, H. L. 1948. 'Natural evaporation from open water, bare soil and grass', Proc. R. Soc. London, Ser. A, $193,120-146$.

Rowntree, P. R. 1988. 'Review of general circulation models as a basis for predicting the effects of vegetation change on climate', In Reynolds, E. R. C. and Thompson, F. B. (eds) Forests, Climate and Hydrology: Regional Impacts, The United Nations University, Kefford Press, Singapore, pp. 162-196.

Rowntree, P. R. and Sangster, A. B. 1986. 'Remote sensing needs identified in climate model experiments with hydrological and albedo changes in the Sahel', in Proceedings of ISLSCP Conference, Rome, December 1985, ESA Pub. No. SP-248, pp. 175-183.

Sellers, P. J. and Dorman, J. L. 1987, 'Testing the Simple Biosphere model (SiB) using point micrometeorological and biophysical data', J. Climate Appl. Meteorol., 26, 622-651.

Sellers, P. J., Mintz, Y., Sud, Y. C. and Dalcher, A. 1986. 'A simple Biosphere Model (SiB) for use within general circulation models', J. Atmos. Sci., 43, 505-531.

Shuttleworth, W. J., Gash, J. H. C., Lloyd, C. R., McNeil, D. D., Moore, C. J. and Wallace, J. S. 1988. 'An integrated micrometeorological system for evaporation measurement', Agric. For. Meteorol., 43, 295-317.

Warrilow, D. A., Sangster, A. B. and Slingo, A. 1986. Modelling of Land Surface Processes and their Influence on European Climate, Meteorological Office, Met. 0 20, Tech. Note DCTN 38, pp. 92.

West, L. T., Wilding, L. P., Landeck, J. K. and Calhoun, F. G. 1984. Soil Survey of the ICRISAT Sahelian Center, Niger, West Africa, Soil and Crop Science Department/Tropsoils, Texas A and M, pp. 66. 